\title{
Новый сорт озимой мягкой пшеницы Обская озимая
}

\author{
К.К. Мусинов $\bowtie$ А.С. Сурначёв, В.Е. Козлов, В.И. Пономаренко, Н.Н. Ермошкина
}

\begin{abstract}
Аннотация: Озимая пшеница имеет существенное преимущество перед яровой за счет более продолжительного использования агро- и биоклиматических ресурсов. В годы с неблагоприятными климатическими условиями для яровых зерновых, такими как сильная засуха и ранние заморозки, озимая пшеница является страховой культурой. Посевные площади озимой пшеницы в России, по сравнению с яровой пшеницей, постепенно увеличиваются. В последние годы в Сибири также происходит расширение клина озимой мягкой пшеницы, в основном за счет внедрения в производство новых сортов с высокими показателями зерновой продуктивности и зимостойкости. В статье дано описание нового сорта озимой пшеницы Обская озимая. Сорт включен в Государственный реестр селекционных достижений, допущенных к использованию по Западно-Сибирскому (10-му) региону, в 2018 г. Достоинства нового сорта - высокая урожайность в сочетании с зимостойкостью. Наибольший вклад в формирование высокой урожайности сорта дали высокая озерненность и коэффициент кущения.
\end{abstract}

Ключевые слова: селекция; новый сорт; озимая мягкая пшеница; Обская озимая; зимостойкость; урожайность; озерненность; продуктивность.

Благодарности: Работа поддержана бюджетным проектом ИЦиГ СО РАН № 0324-2019-0039-С-01.

Для цитирования: Мусинов К.К., Сурначёв А.С., Козлов В.Е., Пономаренко В.И., Ермошкина Н.Н. Новый сорт озимой мягкой пшеницы Обская озимая. Письма в Вавиловский журнал генетики и селекции. 2020;6(2):60-64. DOI 10.18699/Letters2020-6-09

\section{New cultivar of winter common wheat Obskaya winter}

\author{
K.K. Musinov $\bowtie$, A.S. Surnachev, V.E. Kozlov, V.I. Ponomorenko, N.N. Ermoshkina
}

Abstract: Winter wheat has a significant advantage over spring wheat due to the longer use of agro- and bioclimatic resources. In years with unfavorable climatic conditions for spring grains, such as severe drought and early frosts, winter wheat is an insurance crop. According the crop area of winter wheat in Russia is gradually increasing in comparison with spring wheat. In recent years, Siberia has also been expanding the wedge of winter common wheat, mainly due to the introduction of new cultivars into production. In recent years, significant progress has been made in the breeding of winter wheat, and cultivars with high grain productivity and winter hardiness have been produced. The article describes a new cultivar of winter common wheat Obskaya ozimaya. The cultivar has been included in the «State register of breeding achievements of the Russian Federation» approved for use in the West Siberian (10 $\left.{ }^{\text {th }}\right)$ region since 2018 year. The advantage of the new cultivar is the formation of a high yield, combined with winter hardiness. The greatest contribution to the formation is due to high number of grains per ear and increased tillering.

Key words: breeding; new commercial cultivar; winter common wheat; Obskaya ozimaya; winter hardiness; yield, grain content; productivity.

For citation: Musinov K.K., Surnachev A.S., Kozlov V.E., Ponomorenko V.I., Ermoshkina N.N. New cultivar of winter common wheat Obskaya winter. Pisma v Vavilovskii Zhurnal Genetiki i Selektsii = Letters to Vavilov Journal of Genetics and Breeding. 2020;6(2):60-64. DOI 10.18699/Letters2020-6-09 (in Russian)

\section{Введение}

Важное направление развития сельского хозяйства Западной Сибири - производство зерна высокого качества. В структуре растениеводства основная роль принадлежит зерновым культурам, из которых более 60\% посевных площадей занимает яровая пшеница. Увеличение объемов производства продовольственного зерна имеет огромное значение для региона. Одним из резервов увеличения производства зерна в Западной Сибири является расширение площади под озимыми культурами. В сельскохозяйственном севообороте они способны существенно разгрузить проведение полевых работ, когда возникает чрезмерное

Сибирский научно-исследовательский институт растениеводства и селекции - филиал Федерального исследовательского центра Институт цитологии и генетики Сибирского отделения Российской академии наук, Новосибирская область, р.п. Краснообск, Россия Siberian Research Institute of Plant Production and Breeding - Branch of the Institute of Cytology and Genetics, Siberian Branch of the Russian Academy of Sciences, Novosibirsk region, Krasnoobsk, Russia

凶e-mail: musinov29@gmail.com

() Мусинов К.К., Сурначёв А.С., Козлов В.Е., Пономаренко В.И., Ермошкина Н.Н., 2020 
напряжение и ощущается нехватка техники. Это, в свою очередь, может привести к нарушению качества работ и срока их выполнения.

Озимая пшеница имеет существенное преимущество перед яровой за счет более продолжительного использования агро- и биоклиматических ресурсов. В годы с неблагоприятными климатическими условиями для яровых зерновых, такими как сильная засуха и ранние заморозки, озимая пшеница является страховой культурой (Потапова, Зобнина, 2017; Сапега, 2017; и др.). Вследствие этого расширение площадей посева озимой пшеницы за счет сокращения посевов яровой может стать одним из факторов устойчивого производства высококачественного зерна в регионе. Озимая пшеница значительно превосходит по урожайности и экономическим показателям возделываемые в зоне зерновые, в том числе и яровую пшеницу (Усовершенствованная агротехнология..., 2014). В России посевные площади озимой пшеницы по сравнению с площадями, засеянными пшеницей яровой, постепенно увеличиваются. Так, если в 2001 г. на озимую пшеницу приходилось 35.9\% (8537 тыс. га), а на яровую 64.1\% (15 226 тыс. га), то в 2019 г. озимая пшеница занимает уже 56.3\% (15802 тыс. га), яровая 43,7\% (12268 тыс. га)ํ. В последние годы в Сибири также расширяется клин озимой мягкой пшеницы, в первую очередь за счет внедрения в производство новых высокопродуктивных и зимостойких сортов (Артемова и др., 2012). По данным филиала ФГБУ «Россельхозцентр», площадь посева озимой пшеницы в Новосибирской области за 10 лет увеличилась в 6.3 раза: с 4.3 тыс. га в 2009 г. до 27.1 тыс. га в 2019 г. ${ }^{2}$

Получение пшеницы высокого качества сдерживается значительной разностью климатических условий и резкими колебаниями почвенных и других факторов, что негативно влияет как на урожай, так и на его качество (Фадеева и др., 2016). Озимая пшеница обладает высоким биологическим потенциалом продуктивности, использование которого в значительной степени зависит от условий выращивания (Фадеева и др., 2018). Как показывает практика возделывания озимой пшеницы в Сибири, можно проследить по годам неустойчивую урожайность этой культуры. Она обусловлена частой гибелью растений в зимний период, связанной с агроклиматическими условиями. Известно несколько причин гибели озимых, к основным из них следует отнести вымерзание в бесснежный осеннее-зимний период, выпревание при высоком снежном покрове в ранневесенний период и выпадение растений в период отрастания при неблагоприятных гидротермических условиях весенне-летнего периода.

В решении этой проблемы основная роль принадлежит селекции (Мальцева и др., 2014). В последние годы достигнуты значительные успехи в селекции озимой пшеницы. За 2001-2019 гг. в Госреестр селекционных достижений включены 11 новых сортов сибирской селекции: Омская 4, Омская 5, Жатва Алтая, Зимушка, Новосибирская 32, Новосибирская 40, Новосибирская 51, Новосибирская 3, Новосибирская 2, Прииртышская, Обская озимая (см. рисунок).

\footnotetext{
https://ab-centre.ru/news/posevnye-ploschadi-pshenicy-v-rossiiitogi-2019-goda

2 https://rosselhoscenter.com
}

По мнению А.С. Образцова (1981), в селекции каждая культура требует особых методов, тем не менее основными методами получения скороспелых и продуктивных сортов являются гибридизация и отбор. Они и лежат в основе всех остальных методов селекции. Отдаленная гибридизация - один из наиболее результативных методов получения зимостойкого исходного материала для селекции озимой пшеницы. Метод отдаленной гибридизации, как никакой другой, способствует значительному увеличению генофонда культурных растений (Цицин, 1979). При использовании этого метода происходят различные структурные изменения хромосом, такие как транслокации и замещения, что способствует передаче части генетической информации между разными видами. Полученные интрогрессивные формы могут служить только донорами для улучшения современных сортов пшеницы. Такие формы не подходят для непосредственного использования в производстве, так как обладают, как правило, одним или двумя хозяйственно ценными признаками (Максимов, 2011).

В СибНИИРС - филиале ИЦиГ СО РАН в лаборатории под руководством В.М. Чекурова при помощи гибридизации с использованием инбредных клонов пырея сизого (Elytrigia intermedia (Host) Nevski) и зимостойких форм озимой пшеницы создано большое генетическое разнообразие гибридных форм озимой пшеницы (Шумный и др., 1992). На основе пшенично-пырейных гибридов собран селекционный материал, послуживший основой для получения конкурентоспособных сортов озимой пшеницы Новосибирская 32, Новосибирская 40, Новосибирская 51 (Козлов, 2013). Таким образом, увеличение посевных площадей озимой пшеницы в Сибири в большой степени зависит от создания сортов, которые будут сочетать в себе высокий потенциал зимостойкости и продуктивности, а также от усовершенствованной технологии их возделывания.

\section{Методика и условия проведения исследования}

Исследования проведены в 2009-2017 гг. на опытных полях СибНИИРС - филиала ИЦиГ СО РАН, расположенных в центрально-лесостепном Приобском агроландшафтном районе Новосибирской области. Почва опытного участка выщелоченный чернозем с содержанием гумуса, по Тюрину, в пахотном горизонте 5.4-5.7\%; фосфора подвижного, по Чирикову, - 13.01 мг/100 г; калия обменного - 7.75 мг/100 г почвы; $\mathrm{pH}$ водный -6.8 .

В годы исследований (2009-2017) погодные условия были контрастными как по температурному режиму, так и по влагоообеспеченности. Прекращение вегетации (переход через $+5^{\circ} \mathrm{C}$ ) приходилось на первую и вторую декады октября. Снежный покров устанавливался в конце октября (24.10.2016 - ранний срок) или в первой и второй декадах ноября (20.11.2011 - поздний срок) и достигал в марте 3085 см. Наиболее снежной зима была в 2013 г., высота снежного покрова составила 65-85 см (147.6\% от нормы). Температура на глубине узла кущения не опускалась ниже $-14^{\circ} \mathrm{C}$.

Поля СибНИИРС освобождаются от снега в первой декаде апреля (01.04.2012 - ранний сход) или в начале третьей декады (21.04.2010 - поздний сход снега). Начало весенней вегетации наступало в конце первой декады апреля 


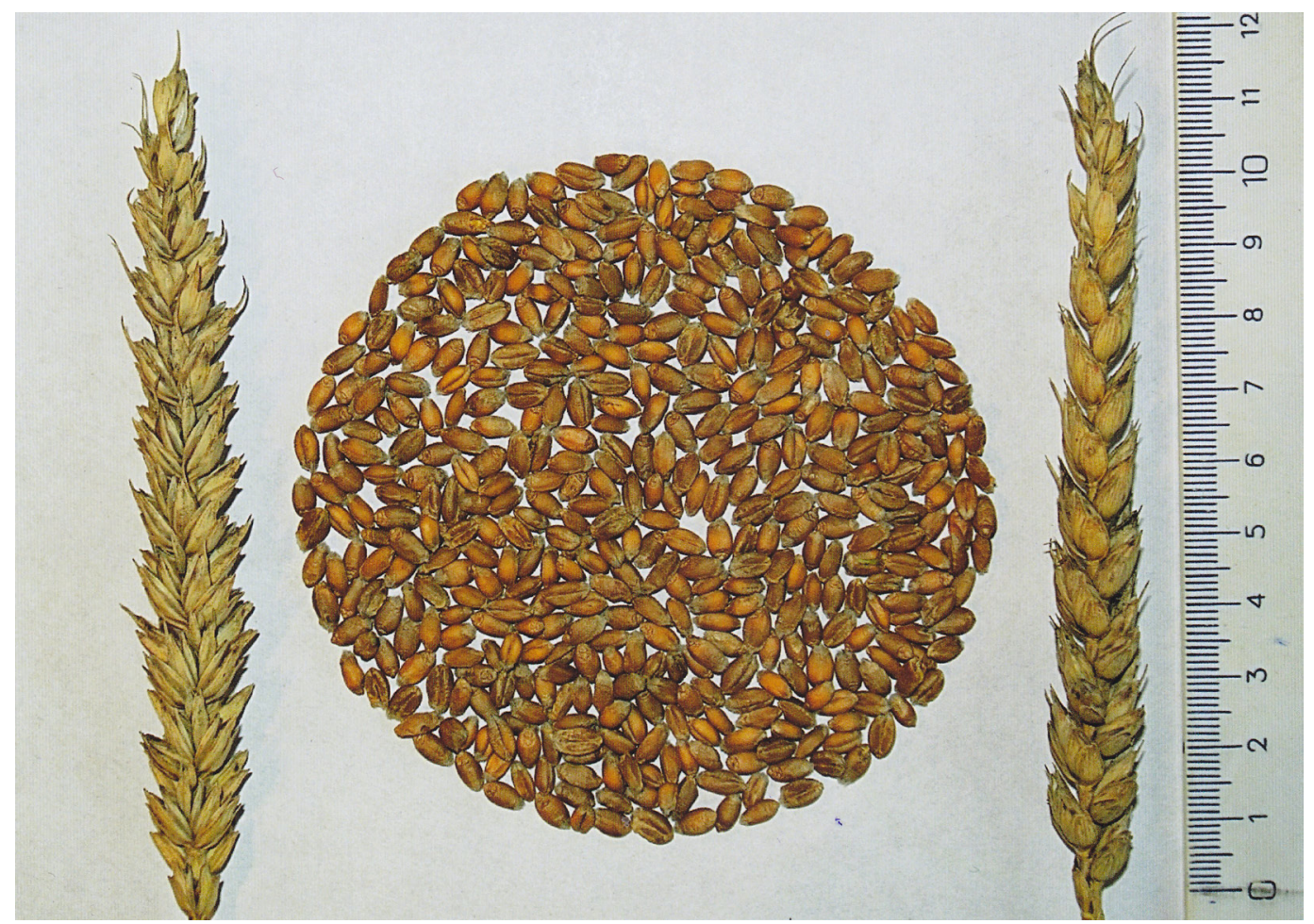

Зерно и колос сорта озимой мягкой пшеницы Обская озимая

(10.04.2012 - ранний срок) или в конце третьей декады (26.04.2010 - поздний). Продолжительность периода отсутствия вегетации в течение проведенных исследований варьировала от 172 до 194 дней. По теплообеспеченности зона исследований относится к умеренно теплому, недостаточно увлажненному району. Продолжительность теплого периода со среднесуточной температурой более $0{ }^{\circ} \mathrm{C}$ составила 185-195 дней.

Агротехника в опытах была общепринятой для лесостепной зоны Сибири. Опыт закладывался по методике Госкомиссии по сортоиспытанию сельскохозяйственных культур

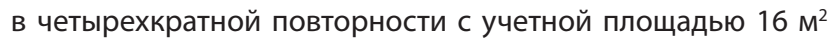
(Методика..., 1989). Посев проведен сеялкой ССФК-7, уборка урожая комбайном Sampo 130 в фазу полной спелости.

Фенологические наблюдения и учет проводили по методике Государственного сортоиспытания сельскохозяйственных культур (Методика..., 1989). Дисперсионный и корреляционный анализ данных - по Б.А. Доспехову (1985) с использованием компьютерной программы СНЕДЕКОР О.Д. Сорокина (2004).

\section{Результаты}

В 2018 г. в Государственный реестр селекционных достижений РФ по Западно-Сибирскому (10-му) региону включен сорт озимой мягкой пшеницы Обская озимая (Государственный реестр..., 2019). Сорт создан методом внутривидовой гибридизации с последующим индивидуальным отбором из гибридной комбинации $\mathrm{F}_{3}$ (Лютесценс ППГ 60-7 × Мироновская 808). Селекционная линия Лютесценс ППГ 60-7 выделена из гибридной популяции [(Аврора $\times$ Elytrigia intermedia (Host) Nevski) $\times$ Ильичевка].
Разновидность lutescens. Куст полупрямостоячий, восковой налет на верхнем междоузлии, колосе и влагалище флагового листа средний. Колос пирамидальный, средней плотности, белый. Остевидные отростки на конце колоса короткие. Нижняя колосковая чешуя на внутренней стороне имеет сильное опушение. Плечо закругленное, средней ширины. Зубец слегка изогнут, короткий. Опушение верхушечного сегмента оси колоса с выпуклой стороны среднее. Зерновка окрашенная. Сорт среднеспелый, длина вегетационного периода 314-346 дней.

Сорт Обская озимая по степени зимней устойчивости находится на уровне стандартного сорта Новосибирская 32 и наиболее распространенного в Новосибирской области сорта Новосибирская 40. В среднем зимостойкость сорта Обская озимая составляет $60 \%$, с колебаниями по годам от 54 до 75\%. Бурой ржавчиной и мучнистой росой Обская озимая поражается на 10-20\% ниже стандарта. Высота растений варьирует от 87 до 129 см (в среднем ниже на 7 см, по сравнению со стандартом). Снижение высоты растений положительно влияет на устойчивость к полеганию, которая в среднем составляет 4.2 балла (табл. 1). Зерно выполненное, крупное, по сравнению с сортом Новосибирская 32, масса 1000 зерен - 34.2 г, натура зерна - 780-816 г/л, стекловидность - 60, что соответствует технологическим качествам зерна I и II класса (ГОСТ 9353-2016). Содержание белка в зерне - 11.5-13.6\%, сырой клейковины в муке - 18.4-25.5\%. Общая хлебопекарная оценка 3.3-4.3 балла. Зерновая продуктивность за годы изучения составила, в среднем, 4.4 т/га, что достоверно выше стандартного сорта на 0.5 т/га. Максимальная урожайность, 5.9 т/га, получена в 2009 г. Высокая урожайность сорта обусловлена комплексом положитель- 
Таблица 1. Продуктивность и элементы структуры урожайности сорта озимой мягкой пшеницы Обская озимая (2009-2017) Table 1. Productivity and the yield structure of a winter common wheat cultivar Obskaya ozimaya (2009-2017)

\begin{tabular}{|c|c|c|c|c|c|}
\hline \multirow{2}{*}{ Признак } & \multirow{2}{*}{$\begin{array}{l}\text { Новосибирская } 32, \text { st* }^{*} \\
\text { среднее }\end{array}$} & \multicolumn{2}{|c|}{ Новосибирская 40} & \multicolumn{2}{|c|}{ Обская озимая } \\
\hline & & среднее & $+/-$ & среднее & $+/-$ \\
\hline Урожайность, т/га & 3.9 & 4.3 & +0.4 & 4.4 & +0.5 \\
\hline Зимостойкость, \% & 64.0 & 64.0 & 0.0 & 60.0 & -4.0 \\
\hline Высота растения, см & 116.0 & 107.0 & -9.0 & 109.0 & -7.0 \\
\hline Устойчивость к полеганию, балл & 3.9 & 4.2 & +0.3 & 4.2 & +0.3 \\
\hline Коэффициент кущения, шт. & 5.6 & 5.7 & +0.1 & 6.5 & +0.8 \\
\hline Масса 1000 зерен, г & 30.9 & 34.4 & +3.5 & 34.2 & +3.3 \\
\hline Длина колоса, см & 9.1 & 8.5 & -0.6 & 10.7 & +1.6 \\
\hline Число колосков, шт. & 17.5 & 18.2 & -0.7 & 19.4 & +1.9 \\
\hline Число зерен с растения, шт. & 187.0 & 194.0 & +7.0 & 231.0 & +44.0 \\
\hline Вес зерна с растения, г & 5.8 & 6.8 & +1.0 & 7.7 & +1.9 \\
\hline
\end{tabular}

* St - стандарт

Таблица 2. Результаты испытаний сорта Обская озимая на госсортоучастках (ГСУ) Новосибирской области (2016-2018) Table 2. Results of tests of the Obskaya ozimaya at the State Variety Testing System of the Novosibirsk region (2016-2018)

\begin{tabular}{|c|c|c|c|c|}
\hline Сорт & Урожайность, ц/га & Зимостойкость, балл & Масса 1000 зерен, г & Устойчивость к полеганию, балл \\
\hline \multicolumn{5}{|l|}{ Северный ГСУ } \\
\hline Новосибирская 32 & 20.9 & 4.0 & 37.4 & 5.0 \\
\hline Новосибирская 40 & 23.4 & 3.9 & 39.3 & 5.0 \\
\hline Обская озимая & 25.5 & 3.9 & 38.2 & 5.0 \\
\hline $\begin{array}{l}\text { Наименьшая } \\
\text { существенная разница }\end{array}$ & \multicolumn{4}{|c|}{1.7} \\
\hline \multicolumn{5}{|l|}{ Маслянинский ГСУ } \\
\hline Новосибирская 32 & 36.3 & 4.3 & 31.5 & 3.1 \\
\hline Новосибирская 40 & 42.2 & 4.3 & 34.5 & 3.5 \\
\hline Обская озимая & 47.2 & 3.6 & 34.6 & 3.9 \\
\hline $\begin{array}{l}\text { Наименьшая } \\
\text { существенная разница }\end{array}$ & \multicolumn{4}{|c|}{2.3} \\
\hline \multicolumn{5}{|l|}{ Венгеровский ГСУ } \\
\hline Новосибирская 32 & 19.0 & 2.7 & 35.4 & 5.0 \\
\hline Новосибирская 40 & 18.5 & 2.6 & 37.9 & 5.0 \\
\hline Обская озимая & 21.5 & 2.7 & 36.5 & 5.0 \\
\hline $\begin{array}{l}\text { Наименьшая } \\
\text { существенная разница }\end{array}$ & \multicolumn{4}{|c|}{1.5} \\
\hline
\end{tabular}

ных хозяйственно ценных признаков. Характерной особенностью является длинный, поникающий к моменту созревания колос, в среднем, за годы исследований его длина составила 10.7 см, при максимальном значении признака 14.7 см. Повышенное число колосков в колосе (до 19.4 шт.) и высокая озерненность колоса обеспечивают высокое число зерен с колоса и, в целом, с растения. Учитывая более высо- кий коэффициент продуктивного кущения, по сравнению с сортами Новосибирская 32 и Новосибирская 40, сорт Обская озимая имеет более высокое число зерна как в колосе, так и на растение. Масса зерна с растения составляет в среднем 7.7 г, у стандартного сорта Новосибирская 32 - 5.8 г, у сорта Новосибирская 40 - 6.8 г. Результаты государственного сортоиспытания в различных агроклиматических зонах Ново- 
сибирской области показали достаточно высокую зерновую продуктивность сорта Обская озимая по сравнению с сортами Новосибирская 32 и Новосибирская 40 (табл. 2). При равной зимостойкости сорт Обская озимая по урожайности достоверно превзошел сорт-стандарт Новосибирская 32 на всех госсортоучастках Новосибирской области. Наибольшая урожайность (4.97 т/га) отмечена в 2018 г. на Маслянинском сортоучастке.

\section{Заключение}

Достоинство нового сорта озимой мягкой пшеницы Обская озимая заключается в формировании высокой зерновой продуктивности, обусловленной высокими показателями озерненности, количеством колосков в колосе и продуктивных колосьев на растение. Сорт включен в Государственный реестр селекционных достижений по 10-му региону Западной Сибири в 2018 г. Рекомендуется для возделывания в I-IV зонах Новосибирской области (подтаежная, северная лесостепь низменности и предгорий).

Учреждение-оригинатор: Сибирский научно-исследовательский институт растениеводства и селекции - филиал ИЦиГ СО РАН (Новосибирск).

Авторы сорта: В.И. Пономаренко, Г.В. Пономаренко, Г.В. Артёмова, А.В. Мединский, В.Е. Козлов, И.В. Михайлапов.

\section{Список литературы/References}

Артемова Г.В., Пономаренко В.И., Степочкин П.И. Формирование признаков продуктивности и устойчивости озимых культур при различных сроках сева. В кн.: Современные проблемы селекции и семеноводства сельскохозяйственных культур. Новосибирск: Россельхозакадемия ГНУ СибНИИРС, 2012:5-9.

[Artemova G.V., Ponomarenko V.I., Stepochkin P.I. Formation of traits of productivity and stability of winter crops at different dates sowing In: Modern problems of breeding and seed production of crops. Novosibirsk: the Russian Academy of agricultural Sciences of GNU SibNIIRC 2012:5-9. (in Russian)]

Государственный реестр селекционных достижений, допущенных к использованию. Сорта растений (официальное издание). М.: ФГБНУ «Росинформагротех», 2019;1.

[The state register of breeding achievements allowed for use. Plant varieties (official publication). Moscow: FSINI Rosinformagrotekh, 2019;1. (in Russian)

Доспехов Б.А. Методика полевого опыта. М.: Агропромиздат, 1985. [Dospekhov B.A. Technique of field experience. Moscow: Agroprom Izdat, 1985. (in Russian)]

Козлов В.Е. Агротехнические и селекционные слагаемые успеха внедрения мироновских сортов озимой пшеницы в СССР как основа для работы по внедрению в Сибири вновь созданных сортов, зимостойких в условиях региона. Вавиловский журнал генетики и селекции. 2013;17(3):541-557.

[Kozlov V.E. Agricultural and breeding prerequisites for successful introduction of Mironovka winter wheat varieties in the USSR as the base for introducing new varieties resistant to Siberian winter. Vavilovskii Zhurnal Genetiki i Selektsii = Vavilov Journal of Genetics and Breeding. 2013;17(3): 541-557. (in Russian)]

Максимов Н.Г. Внутривидовая и межродовая гибридизация в селекции пшеницы мягкой озимой. Селекция и семеноводство. 2011;99:30-38.

[Maksimov N.G. Intraspecific and intergeneric hybridization in the selection of soft winter wheat. Breeding Seed Production. 2011;99:3038. (in Russian)]
Мальцева А.Т., Банникова Н.Ю., Филиппова Е.А., Ефимова А.Г. Озимая пшеница в Уральском регионе. Аграрный вестник Урала. 2014;6:14-18.

[Maltseva A.T., Bannikova N.Y., Filippova E.A., Efimova A.G. Winter wheat in the Ural region. Agrarian Bulletin Urals. 2014;6:14-18. (in Russian)]

Методика Государственного сортоиспытания сельскохозяйственных культур. М.: Госагропром, 1989.

[Methodology of the State variety testing of agricultural crops. Moscow: Gosagroprom, 1989. (in Russian)]

Образцов А.С. Индивидуальный отбор. Биологические основы селекции растений. М.: Колос, 1981.

[Obrazov A.S. Individual selection. Biological bases of plant selection. Moscow: Kolos, 1981. (in Russian)]

Потапова Г.Н., Зобнина Н.Л. Результаты изучения сортов озимой пшеницы в Свердловской области. Зерновое хозяйство России. 2017; 1:55-59.

[Potapova G.N., Zobnina N.L. Results of studying winter wheat varieties in the Sverdlovsk region. Grain Farming in Russia. 2017;1:55-59. (in Russian)]

Сапега В.А. Урожайность, интенсивность и стабильность сортов озимой пшеницы в условиях Северного Зауралья. Вестник С.-х. науки. 2017;1:42-44.

[Sapega V.A. Productivity, intensity and stability of winter wheat varieties in the conditions of the Northern TRANS-Urals. Vestnik Agricultural Science. 2017; 1:42-44. (in Russian)]

Сорокин О.Д. Прикладная статистика на компьютере. Новосибирск: Изд-во НГАУ, 2004.

[Sorokin O.D. Applied statistics on a computer. Novosibirsk: Publishing house of Novosibirsk state agrarian University, 2004. (in Russian)]

Усовершенствованная агротехнология озимой пшеницы, адаптированная к лесостепному агроландшафту Западной Сибири (на примере Омской области). Омск: Литера, 2014.

[Improved agrotechnology of winter wheat adapted to the foreststeppe agricultural landscape of Western Siberia (on the example of the Omsk region). Omsk: Litera, 2014. (in Russian)]

Фадеева И.Д., Валиллулина Г.Н. Надежда - новый сорт озимой мягкой пшеницы, адаптированный к условиям Среднего Поволжья. Зерновое хозяйство России. 2016;3(44):41-44.

[Fadeeva I.D., Valillulina G.N. Nadezhda - a new variety of winter soft wheat adapted to the conditions of the Middle Volga region. Grain Economy Russia. 2016. 2016;3(44):41-44. (in Russian)]

Фадеева И.Д., Тагиров М.Ш., Газизов И.Н. Результаты селекции озимой пшеницы на качество зерна в Татарском НИИСХ. Зерновое хозяйство России. 2018;2(56):34-37.

[Fadeeva I.D., Tagirov M.Sh., Gazizov I.N. Results of selection of winter wheat for grain quality in the Tatar research Institute. Grain Economy Russia. 2018;2(56):34-37. (in Russian)]

Цицин Н.В. Проблемы отдаленной гибридизации: сб. науч. ст. АН СССР, Главный ботанический сад; под ред. Н.В. Цицина. М.: Наука, 1979:5-20.

[Tsitsin N.V. Problems of Distant Hybridization. Problems of distant hybridization: Sat. scientific Art. USSR Academy of Sciences, Main Botanical Garden; under the editorship of N.V. Tsitsin. Moscow: Nauka, 1979:5-20. (in Russian)]

Шумный В.К., Чекуров В.М., Козлов В.Е., Титков И.П., Митрофанов Н.Г. Проблемы и методические подходы к созданию сортов озимой пшеницы для Сибири. В кн.: Генетические методы в селекции растений. Новосибирск: Наука, Сибирское отд., 1992:180-181.

[Shumny V.K., Chekurov V.M., Kozlov V.E., Titkov I.P., Mitrofanov N.G. Problems and methodological approaches to creating winter wheat varieties for Siberia. In: Genetic methods in plant breeding. Novosibirsk: Science, Siberian branch, 1992:180-181. (in Russian)] 